\title{
Competence-centred Practical Teaching System Construction
}

\author{
Sun Peng
}

\author{
Office of Education Administration, Qi Lu Normal University, Jinan, Shandong 250013
}

\section{Keywords: Practical teaching, Competence-oriented, Teaching system}

\begin{abstract}
With the increasing demand for applied talents in the economic society, practical teaching has begun to receive keen attention from universities and society. Practical teaching should focus on ability training, build a practical teaching system, integrate experimental teaching content, reform the practical teaching model, straighten the practical teaching management system, and establish a scientific and reasonable practical teaching quality assurance system and a practical teaching evaluation system.
\end{abstract}

\section{Introduction}

The goal of talent training in local universities and colleges is cultivating practical talents. Its orientation for running schools is basically determined at the level of "teaching and practical" . As for undergraduate level education, attention should be paid to imparting of basic knowledge. As a training orientation for practical talents, attention should be paid to the actuality of production, practice, and management, to the economic and social activities, to cultivate and apply knowledge to analyze problems and solve problems. Students also should be cultivated to adapt to society, and entrepreneurship development.

The practical teaching system is the main carrier for improving students' abilities. It involves practical teaching content arrangement, teaching mode, teaching methods and other aspects. Its design philosophy should clearly answer two questions. One is the goal of cultivating, that is "to cultivate what kind of engineering practice abilities" . the other is cultivating program like "how to cultivate this ability". For advanced practical undergraduate education, the setting of its practical teaching system should highlight the characteristics of practical talents training, and focus on cultivating high-quality talents who are welcomed by the society and can solve specific technical and management problems in production.

\section{The Basic Ideas of Competence-Centered Practical Teaching}

Practical teaching requires higher education institutions aiming at professional training objectives to systematically organize students to acquire various types of instructional forms for the purpose of acquiring perceptual knowledge, conducting basic skills training, enhancing practical abilities, cultivating comprehensive qualities, and improving independent work ability and scientific research experimentation ability. Practical teaching is independent of theoretical teaching and complements each other, which together constitute a complete teaching system of the university.

Practical Teaching And Theoretical Teaching Of Equal Importance Concepts

We should understand the relationship between practical teaching and theoretical teaching, insist that practical teaching and theoretical teaching should be emphasized. This is because, as the two aspects of teaching, practical teaching and theoretical teaching have their own lengths and cannot be ignored. Adhering to the principle of paying equal attention to development is not to develop in isolation, but to focus on the overall needs of teaching, and to achieve common development through mutual coordination and mutual promotion. We must reform the university curriculum system that emphasizes theory than practice, emphasizes professionalism than foundation, emphasizes knowledge than light capabilities. We must establish a foundation for "broadening the profession, strengthening practice, highlighting innovation, and paying attention to comprehensiveness" . this guide us to set a practical teaching system that combines with theory. 


\section{Competence-Oriented Concept}

Competence orientation is to transform traditional professional education into quality education, to establish the concept of integration of knowledge, ability, and quality, to let students as the subject of learning, to strengthen the concept of training students' abilities, to establish the concept of teaching students in accordance with their aptitude and encourage their individual development. The teaching level is diversified, and the cultivating concept is diversified. In the teaching process, we should combine book knowledge and practical experience, combine theories and methods of the discipline. We should teach students not only the ready-made knowledge, but also guide students to think independently, to actively explore unknown areas, and to give full play to students' subjective initiative. It not only cultivates the students' rational thinking ability, but also builds students' solid practical and creative abilities so that they can be comprehensively improved in terms of basic theory, scientific literacy, innovation ability, and adaptability to social changes.

\section{Students-Centered Concept}

In the practical teaching process, students should be taken as the center. Students' actual conditions are fully considered, and appropriate strategies and methods should be used to guide and train students. Student-oriented should be first converted from the "teaching" as the center to the "learning" as the center of change, give full play to the student's main role. Secondly, we should fully consider the student's personality differences, develop a diversified teaching objectives and requirements. Last we should improve practical teaching methods, create a good learning atmosphere, and encourage students to practice and develop independently.

\section{The Idea Of Systematic Advancement}

Planing and organizing practice teaching as a whole. First of all, it is clear that practical teaching is a complete teaching system. In the planning of practical teaching, we must start from the construction of a practical teaching system and do a good job of the overall design. Second, we should pay attention to the mutual and effective connection of various practice links, and the teaching arrangement should be gradual and scientific. They are integrated throughout the curriculum system. Last, the key points should be highlighted, and the key links in the cultivation of practical abilities should be well grasped, with key breakthroughs driving the overall development of practical teaching.

\section{The Overall Structure of Practical Teaching System Centered on Ability Cultivation}

\section{Practical Teaching Training Plan Should Be Forward-Looking And Systematic}

The school takes into account as much as possible the characteristics of students, the trends in professional development, and the focus and intersection of practical teaching content. The design of the program is as concise, clear, and flexible as possible. It focuses on the operation and implementation effect of the program. Each professional practice training program should focus on the organic combination of personality and commonality. It is necessary to achieve the purpose of professional training and consider the improvement of students' basics quality.

\section{Arrangements of Practical Teaching Should Be Gradual and Scientific}

Fundamental practices such as basic experiments, cognitive internships, and social surveys should be arranged in the first and second school years. Curriculum design, professional internships, and other professional practices are more appropriate in the second and third academic years. comprehensive and research-oriented practices like graduation thesis and graduation practice are arranged in the fourth academic year. Scientifically and rationally arranging various practical sessions aims to promote students to connect theory with practice, develop their ability to analyze problems, solve problems, and work independently. At the same time we should improve their practical skills and perception of production organization and production management.

\section{Practical Teaching Content Should have Distinctive Features}

The practical teaching of applied universities is closely linked with the reality of life . Every major should meticulously design every experiment and training project to cultivate students' skills in application and development. In some foreign universities and colleges on the wall of the 
training room, they often display the representative products in the professional development process or outstanding works in previous student training. Students browsing these works are a kind of learning. In some universities, the design of their training content is unique. For example, in order to give students a comprehensive understanding of the principle of the flowmeter, a flow meters training device can be specifically designed to provide all types of flow. The meter is connected in series on a circulating pipe. Students can use the meter to measure all the flow meters by turning on the circulating pump. In the comparison, the working principle of various flow meters can be further understood.

\section{Overall Construction of Practical Teaching System Centered on Ability Cultivation}

The practical teaching system is an organic composed of goals, curriculum, teachers, students, evaluation and other elements. It includes four parts: the target system, content system, security system, and evaluation system.

\section{Construct Target System of Practical Teaching}

The practical teaching system should focus on the student's employment position and development needs. It should be built around the requirements of the professional talents' comprehensive quality and practical ability training. The overall goal of practical teaching is to train students' professional skills and technical literacy through practical teaching, so that students have a strong sense of innovation and comprehensive ability. They can quickly, effectively, and creatively solve practical problems in their work. According to the quality and ability components, the overall goal of practical teaching is further broken down into the following sub-goals.

Professional cognitive goals are to form the cognition of the course and specialty. Correctly understand the first line of production, construction, management, and service. The purpose and significance of practice are established as a front-line service awareness.

Professional skills goals are grasping the common technology of future positions, meeting the basic requirements of the profession, being able to have characteristics in certain aspects. Students can use one or several technologies to solve practical problems in the practical environment, develop rigorous work style, master the science working methods and methods for exploring new knowledge and new technologies.

Comprehensive application capability goals are comprehensively mastering relevant professional knowledge and professional skills, and integrating them into professional application practice to effectively solve practical problems. Students are able to withstand the pressures of modern social scientific progress and technological competition, have strong adaptability to the development of professional technologies, have higher competence, such as unity, collaboration, and dedication, have professional ethics and safety awareness.

Entrepreneurship and innovation ability goals are grasping creative thinking methods, having a strong sense of innovation and innovation, and having the ability to use professional knowledge and technology for employment and entrepreneurship.

The skills and quality goals that can support professional and technical skills. Students should have strong computer application ability, foreign language expression application ability, quantitative analysis and mathematical modeling ability, interpersonal communication and communication skills and good physical and mental quality.

\section{Constructing Content System of Practical Teaching}

According to the practical teaching goals, the practice teaching content is systematically designed and divided into 7 content modules : experimental teaching modules, curriculum design modules, internships (training) modules, social practice modules, graduation design (thesis) modules, and second classroom activity modules.

\section{Construct Security System of Practical Teaching}

In order to achieve the overall goal of cultivating students' innovative and practical abilities, the overall design of theoretical teaching and practical teaching is to be considered. The four-year practical teaching can be considered as a whole, and a four-year integrated independent operation 
mechanism for practical teaching can be established. Integrate closely with practice, knowledge and practice, break down disciplines and professional barriers, organically combine "knowledge, meeting, and being" , integrate teaching content, and combine experiments, internships, design, production, and debugging. Formulate and compile a set of effective teaching series including experimental (practical) outlines, experiments (practice) tutorials, assessment scoring standards and methods, experimental (practical) teaching management rules and regulations, and safety Operational procedures, safety management systems, etc.

We must build a high-level "dual-teacher" teacher team. Through the introduction of professional and business experts with strong practical ability and theoretical basis to teach at universities or colleges, or send teachers to use the holiday to the training of enterprises and institutions. We can require professional theory teachers to pass the relevant professional qualification certificate examination within a limited time to create a "dual division type". The second team of teachers is equipped with excellent experimental and practical instructors. experimenters also required to master experimental techniques and methods. internships, practical training instructors are also demanded to participate in relevant job skills training and obtain a certificate. We can also build an off-campus practical teaching instructor team and hire outside school to enrich the curriculum. The technical backbone of the examination serves as a part-time practice instructor.

The establishment of practical teaching bases in schools are mainly experimental teaching centers, laboratories of various specialties, internship (training) rooms, and internship (training) factories. In order to solve the problem of students' on-site practice, the school can built a number of practice bases that can simulate the on-site environment according to professional characteristics, providing students with experiments and practical places that can fully simulate the on-site environment. The problem of being unable to practice can significantly improve the effectiveness of the internship. In addition, the school can establish a number of on-campus innovation practice bases to foster innovation and practice capabilities. The school has set up "curriculum ability, innovation credits", as long as you complete the practice project as required, you can get the corresponding credits. We can establish off-campus practice teaching sites, mainly outside school internships (training) bases, and cooperative bases for production, education and research. Schools and well-known enterprises in developed regions, in line with the principle of "mutual benefit, cooperation and mutual development" . We can sign the "Agreement on Co-constructing Practice Bases for Undergraduates" and establish a stable practice base outside the school. Third, colleges and universities can share resources, that is, through the experimental centers, training centers, etc., of related institutions to sign sharing agreements to provide public practice teaching platforms.

\section{Constructing Evaluation System of Practice Teaching}

The evaluation of practical teaching mainly includes evaluation of practical teaching conditions, evaluation of practical teaching process, and evaluation of practical teaching effects. Through the establishment of practical teaching evaluation system to promote the reform of practical teaching and strengthen the macro-control of practical teaching

Through the evaluation of practical teaching conditions, schools and related departments can increase investment, accelerate the pace of construction, timely identify and resolve contradictions and problems in construction, improve construction efficiency, and establish relatively advanced and perfect practical teaching conditions as soon as possible. The evaluation of practical teaching conditions should mainly include the evaluation of practical teaching places, the evaluation of practical teaching teachers, and the evaluation of practical teaching techniques.

\section{Conclusion}

Practical teaching is independent of theoretical teaching and complements each other in the process of education and teaching, which together constitute a complete teaching system of the university. Undergraduate colleges and universities should form the basic concept of competence-centered practical teaching, construct the practical teaching system as a whole centering on competence 
cultivation, and build a practical teaching system centering on ability cultivation.

\section{Reference}

[1]Cao Shengli, Innovation and entrepreneurship education calls for simulation teaching and experiential courses [J]. Experimental Technology and Management, 2009,26(8):1-4

[2] Zhang Zhongfu. Thoughts on Practice Teaching Mode in Higher Vocational Education [J]. Vocational Education Forum, 2004(8):50-51

[3] Zhao Xianghua, Analysis of Practical Teaching Quality Guarantee System in Applied University[J]. Education Research, 2008(9):105-106

[4] Niu Changsong. Research on Entrepreneurship Education in British Universities [M]. Shanghai: Xuelin Press, 2009

[5] Zhang Quanfu, The Basic Orientation of Competence Standard of Higher Vocational Education [J]. Vocational Education Forum, 2004

[6] Yu Shulan, Deepening the Reform of Practical Teaching in Colleges and Universities. 2003 (4): $87-67$ 